\title{
Le sacré et le profane : la vie et la mort de Terri Schiavo
}

J'exhorte tous ceux qui honorent Terri Schiavo à continuer d'essayer de créer une culture de la vie où tous les Américains sont les bienvenus, valorisés et protégés, et en particulier ceux qui vivent à la merci d'autrui. L'essence de la civilisation réside dans le devoir qu'ont les forts de protéger les faibles. - George W. Bush, président des États-Unis, le 31 mars 2005.

[L]a réflexion idéologique conteste directement et explicitement la pensée politique. - Bernard Crick, In Defense of Politics, 5e rév., 2000.

$\mathrm{A}$ u cours des dernières semaines de Terri Schiavo, des étrangers du monde entier ont appris à reconnaître les photographies et les vidéos de cette femme lourdement handicapée au sourire que ses parents considéraient comme signe de reconnaissance et ses médecins, comme un réflexe sous-cortical. De l'avis des médecins et des avocats, la conscience que Terri Schiavo avait d'elle-même et sa vie ont pris fin en 1990, lorsqu'elle a été victime d'une arythmie cardiaque et d'une encéphalopathie corticale cérébrale massive qui l'ont laissée dans un état végétatif persistant. L'expression du visage, de même qu'un cycle sommeil-éveil d'apparence «normal», n'était qu'une des facettes de la cruauté de son état.

Les tragédies personnelles liées aux décisions en fin de vie ne dépassent pas normalement le cercle affligé des membres de la famille et des amis. En 1976, le cas de Karen Ann Quinlan a établi aux États-Unis le principe selon lequel la famille peut avoir préséance sur l'État dans les décisions en fin de vie. Après une longue lutte publique, les parents de $M^{\text {me }}$ Quinlan ont été autorisés à débrancher le respirateur qui maintenait cette jeune femme comateuse dans un semblant impitoyable de vie. En dépit de multiples appels interjetés devant les tribunaux, l'affaire Schiavo n'a crée aucun précédent juridique important aux États-Unis. Il se pourrait toutefois que la mort très publique de $\mathrm{M}^{\mathrm{me}}$ Schiavo enclenche des changements législatifs visant à satisfaire l'élément conservateur de la société qui aimerait transformer toutes les questions épineuses en belles théories d'une «culture de la vie».

Le problème avec les slogans de tout acabit, c'est qu'ils obscurcissent les questions complexes que l'on doit étudier clairement. Ainsi, le slogan «culture de la vie» obscurcit les distinctions importantes entre toute une gamme de questions d'éthique allant des décisions en fin de vie, ce qui inclut l'aide au suicide, jusqu'à l'accès à l'avortement, en passant par la recherche sur les cellules souches et le clonage. De nombreux commentateurs ont considéré la lutte pour le «droit de vivre» visant à prolonger l'existence pitoyable de $\mathrm{M}^{\mathrm{m} \text { e }}$ Schiavo comme - une campagne anti-avortement «déguisée». Même le président des États-Unis a utilisé son cas comme prétexte pour faire progresser le programme de son gouvernement en formulant ses condoléances à l'intention des «familles» Schiavo dans les mêmes termes qu'il a utilisés pour décrire la «guerre au terrorisme». C'est ce même gouvernement qui attend impatiemment de s'attaquer à d'autres questions métaphysiques en légiférant au sujet de la recherche sur les cellules souches et de l'avortement, et qu'on a aussi accusé de fonder la composition de comités consultatifs scientifiques nationaux sur les opinions religieuses et morales des scientifiques en question ${ }^{1}$.

Peu d'entre nous pourraient honnêtement affirmer que nous préférerions que les gouvernements et les tribunaux n'aient jamais à intervenir dans des questions comme la dignité de la vie et son caractère sacré, et n'exercent jamais une influence protectrice dans ces questions. Il semble toutefois y avoir peu de doute qu'en Amérique du Nord, l'idéologie et la religion ont commencé à déformer sérieusement le type de dégagement de consensus qui appartient dûment à la politique démocratique.

Où se retrouvent les médecins dans de tels débats? La médecine est une profession profane et scientifique qui doit quand même faire face aux enjeux sacrés de la naissance, la vie et la mort. Dans la pratique, les médecins doivent mettre de côté leurs propres croyances et s'en remettre à l'autonomie morale de chaque patient - ou transférer le soin de ce patient à quelqu'un qui puisse se conformer à cette éthique profane. L'affaire Schiavo nous aura au moins enseigné une leçon pragmatique, soit que les médecins font bien d'encourager les patients à discuter de leurs préférences en fin de vie avec les membres de leur famille et leurs proches longtemps avant ce qu'ils pourraient imaginer comme l'heure de leur mort. En aidant les familles à faire face à cette issue, peu importe quand elle surviendra, le Code de déontologie de l'AMC affirme que les médecins doivent «déterminer dans la mesure du possible les désirs de votre patient au sujet de la mise en œuvre, du maintien ou de l'interruption des traitements essentiels au maintien de la vie». Dans ce numéro, Glenys Godlovitch et ses collaborateurs relatent une affaire peu connue dans le contexte de laquelle un tribunal de l'Alberta a aidé une famille à prendre une telle décision dans un contexte paisible (page $1172)^{2}$. Dans son commentaire, Charles Weijer formule des réflexions sur le rôle que jouent les médecins en aidant les familles à demeurer intactes face aux pressions exercées par les décisions en fin de vie (page 1197) .

L'émotion et la rancoeur qui ont entouré l'affaire Schiavo mettent en évidence l'obligation sociétale plus étendue qui incombe aux milieux médicaux et scientifiques. Ils doivent surveiller les tendances politiques et législatives qui imposent des généralisations morales floues à la majorité, au détriment de la raison, de la compréhension scientifique et, assez souvent, de la compassion. - $7 A M C$

\section{Références}

1. Union of Concerned Scientists. Scientific integrity in policy making. Disponible : www2.ucsusa.org/global_environment/rsi/page.cfm?pageID=1322 (consulté le 4 avril 2005).

2. Godlovitch G, Mitchell I, Doig CJ. Discontinuing life support in comatose patients: an example from Canadian case law. FAMC 2005;172(9):1172-3.

3. Weijer C. A death in the family: reflections on the Terri Schiavo case [éditorial]. JAMC 2005;172(9):1197-8. 